\title{
Clinical features and long-term treatment with pimozide in 65 patients with Gilles de la Tourette's syndrome
}

\author{
LISBETH REGEUR, BENTE PAKKENBERG, RASMUS FOG, \\ HENNING PAKKENBERG \\ From the Laboratory of Neurology, Hvidovre University Hospital, Hvidovre, Denmark
}

SUMMARY During the last seven years 65 patients with Gilles de la Tourette's syndrome have been treated. Pimozide was used as the preferred drug because of our experience of treating other hyperkinesias which indicated fewer side-effects than with haloperidol. Of the 65 patients with Gilles de la Tourette's syndrome, 59 were treated with pimozide alone or in combination with tetrabenazine or clonidine. The dose ranges of pimozide were 0.5-9 mg per day. Eighty-one percent experienced a good clinical response without side-effects. The side-effects seen in our patients were sedation, gain in weight, depression, pseudoparkinsonism and akathisia; acute dystonic reactions, blurred vision, slurred speech and xerostomia did not occur. No cases of tardive dyskinesia were seen.

Treatment of Gilles de la Tourette's syndrome has been difficult and disappointing. In 1961 a marked reduction of motor and vocal tics in a case of Gilles de la Tourette's syndrome was reported after treatment with haloperidol. ${ }^{1}$ These results were soon confirmed by other investigators, ${ }^{2-5}$ who found that such treatment had beneficial effects in up to $89 \%$ of patients. Phenothiazines also have been tried, but had a lesser suppressing effect on tics ${ }^{6}$ and haloperidol has therefore been, and in many centres still is, considered the drug of choice. However, treatment with haloperidol is accompanied by side-effects in many patients.

We have therefore looked for other agents with similar therapeutic action, but with fewer side-effects. Pimozide, a diphenylbutylpiperidine, is one of these; like haloperidol it has a strong blocking effect upon the postsynaptic dopamine receptor, but in several trials on different hyperkinetic diseases, it was found to have fewer side-effects. ${ }^{8-16}$ In our treatment of Gilles de la Tourette's syndrome over the last 7 years we have therefore used pimozide as the preferred drug. The aim of the present study has been to investigate the clinical features of Danish Gilles de la Tourette's syndrome patients and to evaluate the effect of treatment.

Address for reprint requests: Professor H Pakkenberg, Hvidovre Hospital, 2650 Hvidovre, Denmark.

Received 16 April 1985 and in revised form 9 October 1985. Accepted 16 October 1985

\section{Material and method}

Sixty-five patients with Gilles de la Tourette's syndrome, 49 males $(75 \%)$ and 16 females $(25 \%)$ were followed from 6-84 months in the out-patients clinic. The diagnosis was made by history and clinical impression according to the criteria of Shapiro et al. ${ }^{5}$

The age of the patients at the time of the investigation, the age at onset and at the time of diagnosis, the average duration of the disease, and the average interval from onset to diagnosis are shown in table 1 . In $38(58 \%)$ of the patients muscular and/or vocal tics were present in the other close family members; of these, $21(32 \%)$ had first degree relatives with tics. There were four Gilles de la Tourette's families represented by eight patients.

Eight $(12 \%)$ of the patients had delayed development of speech. Twelve $(18 \%)$ of the patients had a stammer. Of these eight still stammer. In eight $(12 \%)$ of the patients birth complications such as prematurity and prolonged birth were reported. Two of these patients are intellectually retarded. Two of the patients had neonatal jaundice, which did not require treatment.

The severity of their illness, rated by two of the authors on a 4-point scale from mild to severe according to the criteria given by Shapiro et al, ${ }^{5}$ was mild in two (3\%), moderate in $23(35 \%)$, marked in $28(43 \%)$ and severe in $12(18 \%)$.

The number of the patients with motor and vocal tics at onset and at the time of the investigation is seen in table 2. Examples of obscenities are given in table 3. Four of the patients were left-handed and four ambidextrous.

A CT-scan was performed with an EMI CT 1010 neuroscanner on the first 53 patients. Five double slices with a thickness of $1 \mathrm{~cm}$ were taken. Contrast media were used only when a pathological process was suspected. EEG was not 
Table 1 Details of 65 patients with Gilles de la Tourette's syndrome

\begin{tabular}{lllll}
\hline Age $(y r)$ & Age at onset $(y r)$ & Age at diagnosis $(y r)$ & Duration of disease & Interval from onset to diagnosis \\
\hline $17.8(6-54)$ & $5.8(2-12)$ & $14.8(5-43)$ & $11.9(1-48)$ & $9 \cdot 0(1-37)$ \\
\hline
\end{tabular}

Table 2 Number of patients with motor and vocal tics at onset and time of investigation

\begin{tabular}{|c|c|c|}
\hline Symptoms & Initial & Present \\
\hline $\begin{array}{l}\text { Motor } \\
\text { Facial tics-including eyes, nose, mouth and grimacing } \\
\text { Tongue protrusion } \\
\text { Licking } \\
\text { Head shaking/jerking } \\
\text { Shoulder shrug } \\
\text { Arm jerk, leg jerk } \\
\text { Abdominal jerk } \\
\text { Episodic tension of body } \\
\text { Echo praxia } \\
\text { Copro praxia } \\
\text { Touching-self, others, things } \\
\text { Other complicated movements } \\
\text { Self mutilations } \\
\text { Vocal: } \\
\text { Stammering/stuttering } \\
\text { Hissing } \\
\text { Groaning/gasping } \\
\text { Grunting } \\
\text { Snorting/sniffing/expiratory hisses } \\
\text { Coughing/throat clearing } \\
\text { Screaming/yelling/squealing/yelping } \\
\text { Squeaking } \\
\text { Humming/muttering/“MM"“/"Uhuh" } \\
\text { Lip smacking/sucking/“tsk" "pft” sounds } \\
\text { Guttural sounds/unintelligible words } \\
\text { Accentuate words oddly } \\
\text { Echolalia } \\
\text { Palilalia } \\
\text { Coprolalia }\end{array}$ & $\begin{array}{r}2 \\
1 \\
2 \\
1 \\
4 \\
10 \\
2 \\
2\end{array}$ & $\begin{array}{r}61 \\
17 \\
13 \\
55 \\
46 \\
43 \\
38 \\
27 \\
23 \\
1 \\
26 \\
24 \\
13 \\
\\
8 \\
15 \\
34 \\
40 \\
38 \\
47 \\
26 \\
16 \\
5 \\
12 \\
9 \\
4 \\
22 \\
4 \\
17\end{array}$ \\
\hline
\end{tabular}

Other complicated movements comprise a wide spectrum such as: Hopping/jumping; smelling hands/objects; biting clothes/objects; throwing objects; tongue inserted into throat; jumping and heel clicking; left leg kick \& right arm jerk; and stamping. Self mutilations comprise: Hitting head/body; biting lips/cheeks/fingers; cracking fingers; scratching until bleeding.

systematically performed in our patients, but 27 patients had had an EEG performed elsewhere. Apart from motor and vocal tics, clinical neurological examination was normal.

Therapeutic effect was classified as a good clinical response when remarkable suppression of tics (that is to complete suppression or minimal residual tics) without sideeffects was achieved. The effect was classified as moderate when remarkable tic-suppression was obtained, but tolerable side-effects occurred, not leading to discontinuation. Response was considered poor when remarkable or moderate tic-suppression was achieved, but intolerable side-effects occurred leading to discontinuation. Treatment failure was considered when no or only minimal ticsuppression was achieved.

Treatment with neuroleptics was instituted when patients demonstrated moderate to severe symptoms, were socially disabled and expressed a wish to treatment after information of possible side-effects.

When treatment was found to be necessary we started with pimozide $0.5-1.0 \mathrm{mg}$ per day, and then raised the dose slowly every 7 th day by $0.5-1.0 \mathrm{mg}$ until optimal clinical effect or adverse side-effects occurred. If an optimal effect could not be obtained with $6 \mathrm{mg}$ of pimozide per day the medication was changed to tetrabenazine starting with 12.5 mg per day. This was gradually increased every 7 th day by $12.5 \mathrm{mg}$ until good clinical response or side-effects. With poor response to a maximum dose of $75 \mathrm{mg}$ tetrabenazine per day, pimozide and tetrabenazine were combined by reducing the tetrabenazine dose and by gradually increasing the pimozide dose from $0 \cdot 5-1 \mathrm{mg}$ per day.

A few patients failed to respond adequately to this regimen. These patients were treated with clonidine in low doses $(0.075-0.225 \mathrm{mg}$ per day) initially in monotherapy and later in combination with pimozide.

Table 3 Examples of some of the obscenities used in our patient population

\begin{tabular}{ll}
\hline $\begin{array}{l}\text { Kaeft } \\
\text { Svin }\end{array}$ & $\left.\begin{array}{l}\text {-vulgar expression for shut up } \\
\text { Fisse } \\
\text { Kusse }\end{array}\right\} \begin{array}{l}\text {-swine-rather powerful in Danish } \\
\text { very vulgar expressions for the vulva }\end{array}$ \\
$\begin{array}{l}\text { Pik } \\
\text { Røv }\end{array}$ & $\begin{array}{l}\text {-vulgar expression for the penis } \\
\text { Pis }\end{array}$ \\
$\begin{array}{l}\text { Sgu } \\
\text { Gylle }\end{array}$ & - - - - bys God \\
Lort & - rustic word for farm animal excretions \\
\hline
\end{tabular}


Results

During the follow-up period 59 patients have been treated with pimozide alone or in combination with tetrabenazine (five patients) or clonidine (four patients). Forty-three patients $(\mathbf{7 3} \%)$ experienced good clinical response with no or only transient sideeffects on pimozide alone. Including patients in combination therapy good response without sideeffects was seen in $48(81 \%)$ of the patients. A further five patients $(9 \%)$ showed moderate effect.

The medical treatment during the follow-up period is shown in table 4. Two patients were given haloperidol, one because of lack of motivation for change of previous medication, and the other because of the better clinical and subjective effect of haloperidol than pimozide and tetrabenazine. The number of patients and the daily doses at time of the investigation are listed in table 5. At the time of investigation 15 of our patients were without medication, two patients because of severe side-effects, and 12 patients because of symptoms which did not require medication, or because the patients were socially well-integrated and preferred to live without medication in spite of many tics. One patient had no response to any medication so far.

\section{Side-effects}

Most of our patients experienced transient sedation in the first weeks of treatment and often when doses were increased. Now and then the side-effects appeared before the beneficial effect; we never treated our patients for less than 8 weeks. One patient developed transient Parkinsonism because of increasing the dose too fast. Eleven patients developed moderate to marked side-effects: 10 patients from pimozide and one patient from pimozide + tetrabenazine. Four of the patients had intolerable sedation, four patients gained weight $(6-15 \mathrm{~kg})$, one patient developed restless legs and two patients became depressed. Four patients chose to try another medication from which they now have experienced a good clinical response, while two patients experienced side-effects from several different drugs and in the end chose to discontinue the medication, five chose to continue the medication in spite of side-effects (the four patients with weight-gain and the one patient with restless legs, in whom the akathisia was controlled by a small dose of anticholinergic drugs). Of the 50 patients, who at the time of investigation were on medication, 48 patients are beneficially treated, 43 with a good clinical response, and five with moderate effect. Two patients showed only moderate suppression of tics in periods with aggravation of symptoms. One patient did not respond to any medication (pimozide, tetrabenazine, haloperidol and fluperlapine). Clonidine was not tried, because of the patient's lack of compliance.

\section{Computed tomography}

Fifty-three CT scans were performed on the first 53 Gilles de la Tourette's syndrome patients. Fortyseven were normal. One patient had a small arachnoid cyst in the occipital region. One patient had a suprasellar epidermoid and one patient had a large

Table 4 Number of patients who have been treated with neuroleptica (0-7 years) including those who are not on medication at the time of the investigation, but have been treated at an earlier time

\begin{tabular}{lllll}
\hline Years & Pimozide & $\begin{array}{l}\text { Pimozide in combination with } \\
\text { Tetrabenazine/clonidine }\end{array}$ & Tetrabenazine & Haloperidol \\
\hline $0-1$ & 19 & 5 & 6 & 5 \\
$2-5$ & 23 & 2 & & \\
\hline
\end{tabular}

Table 5 Number of patients and the daily dose at the time of investigation

\begin{tabular}{lll}
\hline Medication & Patient number & Daily dose \\
\hline Pimozide & 24 & $0 \cdot 5-3 \cdot 0 \mathrm{mg}$ \\
Pimozide & 5 & $3 \cdot 0-8 \cdot 0 \mathrm{mg}$ \\
Pimozide p.n. & 8 & $0 \cdot 5-2 \cdot 0 \mathrm{mg}$ \\
Pimozide \& Tetrabenazine & 3 & Pimozide: 1-8 mg, Tetrabenazine: $25-50 \mathrm{mg}$ \\
Pimozide \& Clonidine & 4 & Pimozide: 2-9 mg, Clonidine: $100-225 \mu \mathrm{g}$ \\
Pimozide \& Tetrabenazine p.n. & 2 & Pimozide: 1-2 mg, Tetrabenazine: 25-50 mg \\
Tetrabenazine & 2 & $50-100 \mathrm{mg}$ \\
Tetrabenazine p.n. & 0 & $2-8 \mathrm{mg}$ \\
Haloperidol & 2 & \\
No medication & 15 & \\
& 65 &
\end{tabular}

P.n. ( = pro necessitate) indicates that the medicine is taken in periods alternating with drug-free periods. 
defect in the right temporo-parietal-region. Two patients had asymmetry of the ventricles and one patient had slight cortical atrophy.

\section{$E E G$}

Of the 27 EEGs performed elsewhere, 15 were normal, nine were diffusely abnormal in a mild to moderate degree and three were abnormal to a severe degree but without local abnormality.

\section{Discussion}

The sex distribution, the age at onset and the interval from onset to diagnosis are in accordance with previously reported series. ${ }^{5}$ Rating the severity according to criteria given by Shapiro 5 showed fewer mild cases in our group and rather more patients with marked and severe symptoms, which could be due to the young age of our patients. The more severe cases are referred to us, while the mild cases still are undiagnosed. Fifty-eight per cent of the patients had a family member with tics and in $32 \%$ the relative with tics was of first degree; this is significantly higher than the previously reported $40 \%{ }^{5}$ Seventy-two per cent of the patients showed muscular tics as initial symptom, whereas in $37 \%$ vocal tics were the initial symptoms indicating multiple tics at onset in some of the patients. (These figures may be distorted by the patients or their family because of problems with recollection of symptomatology at onset). None of the patients had coprolalia as the first symptom. Coprolalia was seen in $26 \%$ of our patients. Shapiro $^{17}$ found coprolalia in $33 \%$ of his patients. The list of examples of obscenities given is not complete owing to reluctance of our patients to mention their actual swear words. Echolalia was found in $34 \%$ of the patients, which is in accordance with other reports ${ }^{5}$ while echopraxia was found in a higher proportion. Taken as a whole the patients in our group do not differ significantly from those of other series.

Only one of our patients takes more than $8 \mathrm{mg}$ pimozide per day in periods of aggravation of symptoms. Six of the patients are being treated with 3-8 mg pimozide per day; all the other patients on pimozide therapy are being treated with doses from 0.5-3 mg per day. The doses used are clearly below those employed in other series. ${ }^{161819}$ and may explain why we did not see acute dystonic reactions and why Parkinsonism was seen in only one of our patients. Treatment with anticholinergics has only been necessary in one patient, a case of restless legs.

As pointed out by other authors ${ }^{18}$ it is important to start with a very low dose (0.5-1 mg per day) and to raise the dose very slowly. Children were given one dose in the morning and one in the afternoon, but no evening dose. The same regimen can be used with adults. It is our experience that the treatment response to an increase of pimozide above $8 \mathrm{mg}$ per day is very poor, and it is more advisable to combine pimozide with drugs with a different site of action such as tetrabenazine or clonidine than to increase the dose in patients whose symptoms cannot be controlled on $8 \mathrm{mg}$.

In table 4 only the periods in which the patients received medication was recorded and did not include the drug-free intervals. We encourage our patients to decrease and, if possible, to discontinue medication altogether in the good periods of their illness. So far none of our patients have developed long-term sideeffects, that is tardive dyskinesia. We believe that the strict regimen with the low doses and drug-free intervals is the best way to avoid these.

The superiority of pimozide to haloperidol may be related to its more specific blocking of dopamine and to absence of norepinephrine antagonism. ${ }^{2021}$

In conclusion we treat our Gilles de la Tourette's syndrome patients with mild to moderate symptoms beneficially, but some of the patients with severe symptoms still represent a problem in periods with aggravation of symptoms. In our experience, pimozide is the drug of choice in the treatment of Gilles de la Tourette's syndrome, because it induces fewer side-effects than haloperidol. Like other neuroleptics, however, pimozide implies a risk of long-term adverse side-effects (tardive dyskinesia). More effective therapeutic agents with less adverse side-effects are still needed.

\section{References}

${ }^{1}$ Seignot MJN. Un cas de maladie de Gilles de la Tourette guéri par R 1625. Ann Med Psychol 1961;119:578-9.

${ }^{2}$ Shapiro AK, Shapiro E, Wayne H. Treatment of Tourette's Syndrome with haloperidol, review of 34 cases. Arch Gen Psychiatry 1973;28:92-7.

${ }^{3}$ Brūūn RD, Shapiro AK, Shapiro E, Sweet RD, Wayne H, Solomon GE. A follow-up of 78 patients with Gilles de la Tourette's syndrome. Am J Psychiatry 1976;133:944-7.

${ }^{4}$ Sweet RD, Bruun RD, Shapiro AK, Shapiro E. The pharmacology of Gilles de la Tourette's syndrome (chronic multiple tic). In: Klawans HL, ed. Clinical neuropharmacology, Vol 1. New York: Raven Press 1976.

${ }^{3}$ Shapiro AK, Shapiro E, Bruun RD, Sweet RD. Gilles de la Tourette's Syndrome. New York: Raven Press 1978.

${ }^{6}$ Abuzzahab FS, Anderson O. Gilles de la Tourette's Syndrome: International registry. Minn Med 1973;56:492-6.

${ }^{7}$ Mesnikoff A. Three cases of Gilles de la Tourette's Syndrome treated with psychotherapy and chlorpromazine. Arch Neurol Psychiatry 1959;81:710.

${ }^{8}$ Fog R, Pakkenberg H. Combined Nitoman-Pimozide treatment of Huntington's chorea and other hyperkinetic syndromes. Acta Neurol Scand 1970;46:249-51. 
${ }^{9}$ Fog R, Pakkenberg $\mathrm{H}$. Theoretical and clinical aspects of the Tourette Syndrome (chronic multiple tic). J Neural Transm 1980; suppl 16:211-5.

${ }^{10}$ Pakkenberg H, Fog R. Spontaneous oral facial dyskinesia: Results of treatment with tetrabenazine, pimozide, or both. Arch Neurol 1974;31:352-3.

11 Pakkenberg B, Regeur L, Fog R, Pakkenberg H. Gilles de la Tourette's Syndrome. Experience with 18 patients. Ugeskr Laeger 1982;144:3078-81.

12 Regeur L, Pakkenberg B, Pakkenberg H, Fog R. Combined pharmacotherapy of Gilles de la Tourette's Syndrome. Acta Neurol Scand 1982; 65 suppl 90:308-9.

${ }^{13}$ Debray P, Messerschmitt P, Lonchap D, Herbault M. L'utilization du pimozide en pédopsychiatrie. Nouv Presse Med 1972;1:2917-8.

${ }^{14}$ Ross MS, Moldofsky H. Comparison of pimozide and haloperidol in the treatment of Gilles de la Tourette's Syndrome. Am J Psychiatry 1978;135:585-7.

${ }^{15}$ Shapiro AK, Shapiro E. Clinical efficacy of haloperidol, pimozide, penfluridol, and clonidine in the treatment of
Tourette Syndrome. In: Friedhoff AJ, Chase TN, eds. Gilles de la Tourette Syndrome. New York: Raven Press 1982:383-6.

${ }^{16}$ Shapiro AK, Shapiro E, Eisenkraft MA. Treatment of Gilles de la Tourette syndrome with pimozide. Am J Psychiatry 1983;140:1183-6.

${ }^{17}$ Shapiro AK, Shapiro E. An update on Tourette syndrome. Am J Psychotherapy 1982;36:379-90.

${ }^{18}$ Shapiro AK, Shapiro E. Controlled study of pimozide vs. placebo in Tourette's Syndrome. J Am Acad Child Psychiatr 1984;23:161-73.

${ }^{19}$ Brunn R. Treatment of Tourette Syndrome with pimozide (orap). Tourette Syndrome Association Newsletter 1985;12:5.

${ }^{20}$ Anden NE, Butcher SF, Corrodi $\mathrm{H}$. Receptor activity and turnover of dopamine and noradrenaline after neuroleptics. Eur J Pharmacol 1970;11:303-14.

${ }^{21}$ Seeman P, Lee T. Antipsychotic drugs: direct correlation between clinical potency and presynaptic action on dopamine neurons. Science 1975;188:1217-9. 